College of Rheumatology; BID, twice daily; BMI, body mass index; Cl, confidence interval; FAS, full analysis set; NRI, non-responder imputation

Methods: Data were analysed from six Phase 3 studies for pts who were methotrexate-naïve (NCT01039688) or had an inadequate response to DMARDs (NCT00960440, NCT00847613, NCT00814307, NCT00856544, NCT00853385) and received $\geq 1$ dose of tofacitinib 5 or $10 \mathrm{mg}$ twice daily (BID) or placebo (PBO). Pts were stratified by $\mathrm{BL} \mathrm{BMI}(<25,25$ to $<30, \geq 30)$. Efficacy endpoints (American College of Rheumatology [ACR]20/50/70 response rates at Month [M]6; changes from baseline $[\Delta]$ in Health Assessment Questionnaire-Disability Index [HAQ-DI], Disease Activity Score in 28 joints based on Erythrocyte Sedimentation Rate [DAS28-4(ESR)], DAS28 based on C-reactive protein [DAS28-4(CRP)] and Clinical Disease Activity Index [CDAI] at M3 and M6) were assessed. Non-responder imputation was used for the binary endpoints. No imputation was used for continuous endpoints. No multiplicity adjustment was performed in this post hoc analysis. Results: Overall, 1589, 1611 and 681 pts received tofacitinib 5 and $10 \mathrm{mg}$ BID and $\mathrm{PBO}$, respectively, with 1690,1173 and 1017 pts in the $\mathrm{BMI}<25,25$ to $<30$ and $\geq 30$ categories, respectively. BL demographics were generally similar between BMI categories with the exception of higher rates of diabetes (12.9$14.2 \%$ vs $3.5-9.8 \%)$, hypertension $(53.2-58.9 \%$ vs $22.0-39.8 \%$ ), and use of prior TNFi (23.7-46.8\% vs 15.0-26.9\%), and numerically higher tender (28.8-29.9 vs 23.5-26.9) and swollen joint counts (16.5-17.1 vs 14.5-16.3) and HAQ-DI scores (1.6 vs 1.4-1.5) in the $\mathrm{BMI} \geq 30$ group vs $\mathrm{BMI}<25$ or 25 to $<30$. ACR response rates were significantly higher $(p<0.05)$ in the tofacitinib vs PBO groups, regardless of $\mathrm{BMI}$ category(figure 1). In general, there appeared to be a trend towards lower ACR20/50/70 response rates with increasing BMI at M6 in tofacitinib- and PBOtreated pts; however, confidence intervals $(\mathrm{Cl})$ overlapped. At M6, $\triangle \mathrm{HAQ}-\mathrm{DI}$ was numerically smaller for pts receiving tofacitinib $5 \mathrm{mg} B I D$ with $B M I \geq 30$ vs lower BMlcategories, with overlapping $\mathrm{Cl}$. The $\triangle \mathrm{DAS} 28-4(\mathrm{ESR}), \triangle \mathrm{DAS} 28-4(\mathrm{CRP})$ and $\triangle$ CDAlscores were similar within each treatment group regardless of BL BMI. Generallysimilar trends were observed when stratified by weight.

Conclusions: Results of this post hoc analysis suggest that tofacitinib is associated with improvements in RA outcomes compared with $\mathrm{PBO}$ regardless of $\mathrm{BL}$ BMI category. In both tofacitinib and PBO groups, similar trends in improvements were seen in most endpoints regardless of BMI category, implying that the effect of $\mathrm{BL} B M \mathrm{~B}$ is not specific to tofacitinib. Further investigation is needed to assess the degree of impactof BMI on tofacitinib efficacy.

Acknowledgements: Study sponsored by Pfizer Inc. Medical writing support was provided by $\mathrm{C}$ Viegelmann of CMC and funded by Pfizer Inc.

Disclosure of Interest: A. DikranianGrant/research support from: AbbVie, Mallinckrodt, Pfizer Inc, Speakers bureau:AbbVie, Amgen, Celgene, Mallinckrodt, Pfizer Inc, M. Gonzalez-Gay Consultant for: Pfizer Inc, F. Wellborne Grant/ research support from: AbbVie, BMS, EliLilly, Novartis, Pfizer Inc, Sanofi/Genzyme/Regeneron, Consultant for: AbbVie,BMS, Novartis, Pfizer Inc, Sanofi/Genzyme/Regeneron, Speakers bureau: AbbVie,BMS, Eli Lilly, Novartis, Pfizer Inc, Sanofi/Genzyme/Regeneron, J.Alvaro-Gracia Consultant for: Abbvie, BMS, Eli Lilly, MSD, Novartis, Pfizerlnc, Roche, Sanofi/Genzyme/Regeneron, Speakers bureau: Abbvie, BMS, Eli Lilly,MSD, Novartis, Pfizer Inc, Roche, Sanofi/Genzyme/Regeneron, L. Takiya Shareholder of: Pfizer Inc, Employee of: Pfizer Inc, L. Stockert Shareholder of: Pfizer Inc, Employee of: Pfizer Inc, D. Chapman Shareholder of: Pfizer Inc,Employee of: Pfizer Inc, S. Tatulych Shareholder of: Pfizer Inc, Employee of:Pfizer Inc, P. Dahl Shareholder of: Pfizer Inc, Employee of: Pfizer Inc, J.Curtis Grant/research support from: Amgen, Corrona, Crescendo Bio, Pfizer Inc, Consultant for: AbbVie, Amgen, BMS, Corrona, Eli Lilly, Janssen, Myriad, Roche/Genentech,UCB

DOI: 10.1136/annrheumdis-2018-eular.1284

\section{SAT0128 THE RISK FACTORS FOR SEVERE EXACERBATION OF INTERSTITIAL LUNG DISEASE IN RHEUMATOID ARTHRITIS DURING BDMARD THERAPY}

A. Tanaka ${ }^{1}$, K. Kurasawa ${ }^{1}$, T. Miyao ${ }^{1}$, Y. Takamura ${ }^{1}$, R. Yamazaki ${ }^{1}$, S. Arai ${ }^{1}$, T. Owada', R. Maezawa', M. Arima'. ' ${ }^{1}$ Departoment of Rheumatology, Dokkyo Medical University, Tochigi, Japan

Background: Rheumatoid arthritis (RA) is a systemic inflammatory disease that affects joints and various organs. The lung is one of the most common site of extra-articular involvement. Interstitial lung disease (ILD) is one form of the lung involvement and influences prognosis of the patients. RA-ILD frequently developed acute exacerbation. Once acute exacerbation occurs, the prognosis of patients is poor. However, it is not fully elucidated what the risk factors for severe exacerbation of ILD are.

Objectives: The purpose of thisstudy was to identify the risk factors for severe exacerbation of ILD in RApatients during bDMARDs therapy. The purpose of this study was to identify therisk factors for exacerbation of ILD in RA patients under the bDMARDs therapy.
Methods: A retrospective cohort study. Subjects were consecutive 208 RA patients who were treated with bDMARDs from 2004 to 2015 in our department and received HRCT scan before and during the therapy. Based on HR-CT imaging, pulmonary abnormalities were classified into 4 categories (ILD, nodular lesions, airway disease (AD) and others) and 20 lesions such as ground-glass opacity (GGO), reticular pattern, bronchiolitis and bronchiectasis. We recorded their existence and distribution before andduring the therapy and examined their changes. Severe exacerbation of ILD was judged when patients revealed newly emerging/worsening of ILD lesions regardless of pre-existing pulmonary lesions and deceased or had to stop bDMARDs due to exacerbation of ILD. To identify risk factors, logistic regression analysis was conducted.

Results: Subjects were 208 RApatients, M/F; 64/144, mean age; 59.2 years old, disease duration; 7.9 years positive for RF in $84.1 \%$. bDMARDs used for the longest period were TNFinhibitors in $79.8 \%$ of the subjects, abatacept in $15.4 \%$ and tocilizmab in $4.8 \%$.

Pulmonary abnormalities were found in 146 (70.2\%) of RA patients before bDMARDs (ILD 81,(38.9\%); nodular lesions 45, (21.6\%); and ADs, 115, (55.3\%)). GGO, consolidation, reticular pattern and honey combing was found in $14.8 \%$, $19.8 \%, 51.9 \%$, and $17.3 \%$ of ILD patients. Most of ILD lesions coexisted with ADs During the observation period $(3.26 \pm 2.61$ years), newly emerging/worsening pulmonary lesions were found in $42.3 \%$ of patients and the incidence of which was 13.7/100person year. The incidence of newly development and worsening of ILD were $7.0 / 100$ person years and $1.5 / 100$ person years, respectively.

Severe exacerbation of ILD was developed in 13 patients $(6.3 \%)$ and the incidence of which was 2.0/100 person year. Of 13 patients, 9 died of respiratory failure. All patients with severe exacerbation revealed GGO/consolidation Interestingly, all these active ILD lesions were newly emerging lesions, however, most of the patients had pre-existing pulmonary lesions.

We identified risk factors for severe exacerbation of ILD (Table1). The risk factors for severe exacerbation of ILD were older age and pre-existing pulmonary lesions of ILD and of ADs, particularly reticular pattern, honeycomb and bronchiectasis. Sero-positivity and choice of biologics were not identified as risk factors.

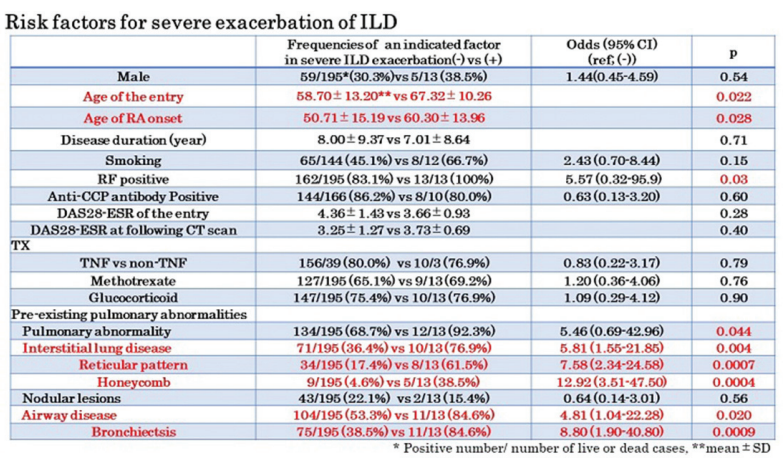

Conclusions: The incidence of severe exacerbation of ILD was 2.0/100 person years. The risk factors forsevere exacerbation of ILD were older age and preexisting reticular pattern, honeycomb and bronchiectasis.

Disclosure of Interest: None declared

DOI: 10.1136/annrheumdis-2018-eular.4346

\section{SAT0129 TRENDS IN THE INCIDENCE OF CARDIOVASCULAR DISEASES IN PATIENTS WITH RHEUMATOID ARTHRITIS IN SPAIN: AN OBSERVATIONAL COHORT STUDY OF HOSPITAL DISCHARGES FROM 1999 TO 2015 (TREND- AR STUDY)}

C. MacíaVilla ${ }^{1}$, R. Mazzucchelli ${ }^{2}$, E. Perez Hernandez ${ }^{3}$, J. Quirós $^{2}$, J. L. Morell Hita $^{4}$, N. Crespí ${ }^{5}$, M. Peña ${ }^{2}$, C. Barbadillo ${ }^{6}$, M. Espinosa ${ }^{6}$, H. Godoy ${ }^{6}$, M. Fernandez Prada ${ }^{7}$, M. Galindo ${ }^{8}$, A. Garcia Vadillo ${ }^{9}$, O. Guzon Illescas ${ }^{2}$, A. Herranz ${ }^{10}$, C. Martinez Prada ${ }^{11}$, C. Morado Quiñoa ${ }^{11}$, V. Villaverde ${ }^{12}$ on behalf o TREND-AR . ${ }^{1}$ Rheumatology, Hospital Universitario Severo Ochoa; ${ }^{2}$ Rheumatology; ${ }^{3}$ Hospital Universitario Fundación Alcorcón; ${ }^{4}$ Rheumatology, Hospital Universitario Ramón y Cajal; ${ }^{5}$ C.S. La Rivota; ${ }^{6}$ Rheumatology, Hospital Universitario Puerta de Hierro, Madrid; ${ }^{7}$ Rheumatology, Hospital Universitario Guadalajara, Guadalajara; ${ }^{8}$ Rheumatology, Hospital Universitario Doce de Octubre; ${ }^{9}$ Rheumatology, Hospital Universitario La Princesa; ${ }^{10}$ Rheumatology, Hospital del Henares;

${ }^{11}$ Rheumatology, Hospital Universitario Clínico San Carlos; ${ }^{12}$ Rheumatology, Hospital Universitario de Móstoles, Madrid, Spain

Background: Several changes have appeard in the last years in the management of Rheumatoid Arhritis (RA), and also a greater awareness about cardiovascular risk has emerged. However, the trend of CVDs in RA in Spain is unknown. 